\title{
Examining Trust in Information Technology Artifacts: The Effects of System Quality and Culture
}

\author{
ANTHONY VANCE, CHRISTOPHE ELIE-DIT-COSAQUE, AND \\ DETMAR W. STRAUB
}

Anthony VAnce is a Ph.D. candidate in Computer Information Systems in the J. Mack Robinson College of Business at Georgia State University and the Université ParisDauphine, Research Center in Management and Organization (DRM/CREPA). His research interests include trust and IT, IS security, internal control, and international issues of IT. Before undertaking his Ph.D., he worked as an IT security consultant for Deloitte.

Christophe Elie-dit-cosaque is a Ph.D. candidate in Information Systems at the Université Paris-Dauphine, Research Center in Management and Organization (DRM/CREPA), and the Georgia State University, J. Mack Robinson College of Business, CIS Department. He holds a B.A. in Management Science and an M.S. in Information Systems from Université Paris-Dauphine, and an M.S. in Management Science from the Institut National des Telecommunications. His research interests include user adaptation to IT, IT innovation, and the effects of IT on managerial work in public administration.

Detmar W. Straub is the J. Mack Robinson Distinguished Professor of Information Systems at Georgia State University. He has conducted research in the areas of computer security, Net-enhanced organizations (e-commerce), technological innovation, international IT studies, and IS research methods. He holds a DBA in MIS from Indiana and a Ph.D. in English from Penn State. He has published over 145 papers in journals such as MIS Quarterly, Journal of Management Information Systems, Management Science, Information Systems Research, Journal of the AIS, Decision Sciences, Organization Science, Communications of the ACM, Information \& Management, Communications of the AIS, IEEE Transactions on Engineering Management, DATA BASE, OMEGA, Academy of Management Executive, and Sloan Management Review. He is currently editor-in-chief of MIS Quarterly and a former senior editor for Information Systems Research and Journal of the AIS; he is also a former coeditor of DATA BASE for Advances in Information Systems. Currently, he is also an associate editor for the Journal of International Management. In the past, he has served as associate editor for Management Science and Information Systems Research, and associate publisher/senior editor/associate editor for MIS Quarterly as well as an editorial board member of a variety of other journals. Former Vice President of Publications for the Association of Information Systems (AIS), he has held roles as coprogram chair for AMCIS and ICIS and was inducted as an AIS Fellow in 2005. 
ABSTRACT: The topic of trust in information technology (IT) artifacts has piqued interest among researchers, but studies of this form of trust are not definitive regarding which factors contribute to it the most. Our study empirically tests a model of trust in IT artifacts that increases our understanding in two ways. First, it sets forth two previously unexamined system quality constructs - navigational structure and visual appeal. We found that both of these system quality constructs significantly predict the extent to which users place trust in mobile commerce technologies. Second, our study considers the effect of culture by comparing the trust of French and American potential users in m-commerce technologies. We found that not only does culture directly affect user trust in IT artifacts but it also moderates the extent to which navigational structure affects this form of trust. These findings show that system quality and culture significantly affect trust in the IT artifact and point to rich possibilities for future research in these areas.

KEY WORDS AND PHRASES: culture impacts, institution-based trust, m-commerce, $\mathrm{m}$-commerce portals, navigational structure, system quality, systems use, trust in the IT artifact, visual appeal.

A LARGE AND GROWING BODY OF RESEARCH has examined the role of trust in e-commerce transactions. Much of this research has looked at the nature of consumer trust placed in institutions supporting e-commerce [29]. Trust in suppliers and communities has also been explored [66, 67]. What has been generally absent from these investigations, however, is a focus on the effects of trust placed in the information technology (IT) artifacts. Recent research has shown that the phenomenon of trust involves not only people $[46,50,86]$ but also IT artifacts—hardware or software that enables tasks [5]. Users place trust in IT artifacts by "relying or depending on infrastructure systems like the Web or relying on specific information systems like Microsoft Excel ${ }^{\mathrm{TM}}$ " [57, p. 330]. One exception to the lack of attention to the topic of trust in IT artifacts is that of Wang and Benbasat [86], who in a seminal study found that consumers place significant levels of trust in IT artifacts when transacting business online. Because there is little work beyond this, Wang and Benbasat [86] call for further research to extend the conceptualization of trust in IT artifacts and identify relevant factors that contribute to their formation. This study is a response to their call.

The objective of this study is to suggest and empirically test a model of trust in IT artifacts. To do so, we examine m-commerce portals [34], Internet-based storefronts of e-commerce sites specifically tailored for mobile devices $[2,77,85]$. We believe that it is especially instructive to examine trust in emerging IT artifacts where, from a commercial point of view, the eventual acceptance or rejection of the artifact is still very much in doubt. Such is the case for technologies relating to mobile commerce, which continue to struggle to find widespread consumer adoption [2]. Studies that explore such artifacts may help to explain how trust might affect the diffusion of new technologies. 
Our model breaks new ground by incorporating system quality characteristics thought to be important in m-commerce scenarios-navigational structure and visual appeal $[47,75]$. We empirically test our model by conducting a free simulation experiment involving a simulated $\mathrm{m}$-commerce portal. One contribution of this study is the finding that system quality attributes significantly influence users' trust in m-commerce portals. These findings have relevant implications for practitioners in that manufacturers such as Apple, Nokia, and Sony are currently seeking ways to dramatically improve the user interface of m-commerce devices and thus spur m-commerce activity [2].

Our model of trust in the IT artifact also incorporates culture as an important component. Culture is an important explanatory factor in the use of information systems (IS) and the Web. It has, for example, been tied to an individual's willingness to become committed to new technologies [80]. But the effect of culture on an individual's trust in IT artifacts is still unexplored territory. Consequently, following the call from Zaheer and Zaheer [91] for more cross-cultural, comparative research to explore in greater depth the linkages between culture and trust, we also investigate this aspect. Our model demonstrates that culture significantly affects user willingness to trust in an IT artifact, suggesting several implications for the design of mobile Web interfaces and IT artifacts in general.

\section{Literature Review, Research Model, and Hypotheses}

BEFORE REVIEWING THE LITERATURE RELEVANT TO TESTING the nomology outlined above, we foreshadow our views in Figure 1, which is the full research model eventually presented for consideration. The model shows direct effects via solid lines and moderating effects as dashed lines affecting paths.

\section{Trust in IT Artifacts}

In recent years, trust has become increasingly recognized for its essential role in encouraging consumers to adopt online modes of commerce [28, 29, 58, 66]. However, a persistent gap in IS trust literature is the effect of the IT artifact on consumers. Most trust-related IS literature has viewed the IT artifact simply as an enabling ingredient of online transactions, focusing instead on vendor- or institution-based effects of trust $[25,26,58,66]$. These extremely valuable insights notwithstanding, recent work has pointed to the major role that the IT artifact can assume in engendering consumer trust. A number of studies have investigated the ability of online software-based recommendation agents to increase consumer trust in online retail sites [71, 87], demonstrating indirectly, at least, that IT artifacts can affect consumer trust.

However, aside from trust in recommendation agents, little empirical research has examined trust in IT artifacts. One exception is the research of Lippert [50], who examined trust placed in various organizational IS and found evidence that predictability, reliability, and technical utility (comprised of perceived usefulness and perceived ease of use [EOU]) are each positively correlated with trust in the IT artifact. The present 


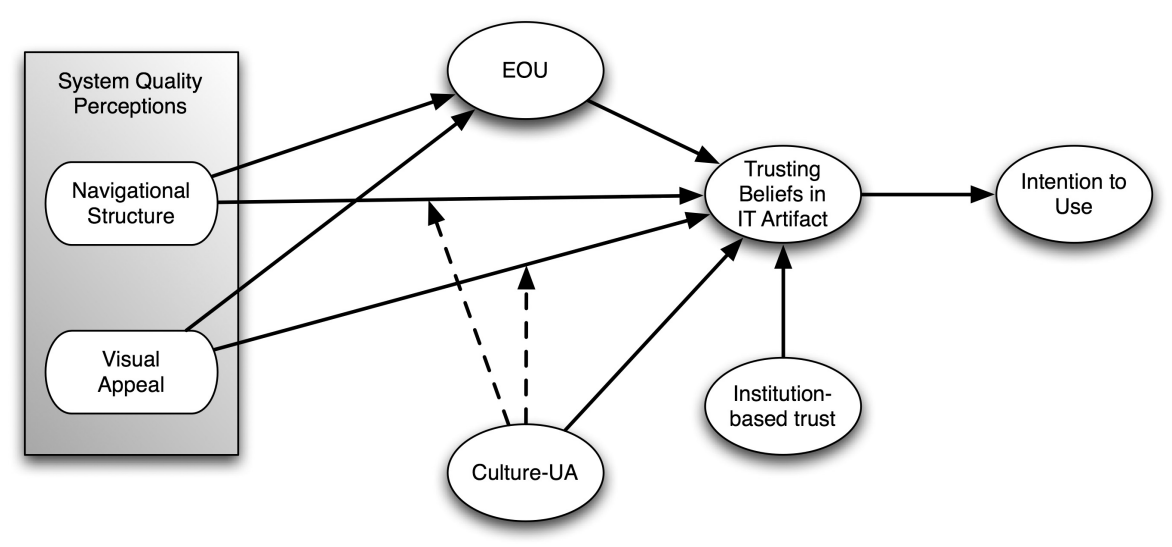

Figure 1. Research Model Showing the Significance of Relationships Notes: $\mathrm{EOU}=$ ease of use; $\mathrm{UA}=$ uncertainty avoidance.

study aims to explore the conceptualization of trust placed in technology by examining other factors that may contribute to trust in IT artifacts and to provide empirical evidence for the relative strengths of these factors on the engendering of trust.

\section{The Effect of Trust on Intention to Use}

Trust researchers have found a strong relationship between trusting beliefs and trusting intentions. According to Fishbein and Ajzen's theory of reasoned action (TRA) [20], beliefs lead to attitudes, which in turn lead to intentions and, ultimately, behaviors. The process of progressing from beliefs to behaviors has been found to be highly amenable to the formation of trust. McKnight et al. [60], adapting Davis's more parsimonious version of TRA [14], theorized that trusting beliefs, trusting intentions, and trusting behaviors comprise the cognitive process by which a truster determines whether or not to place trust in an unknown trustee. Trusting belief is the belief that the trustee has characteristics that would benefit the truster. These beliefs lead to trusting intention, which is the willingness or intention of the truster to rely on the trustee. Finally, trusting intention leads to trusting behavior, which is the act of the truster becoming vulnerable to the trustee in a situation of uncertainty.

This cognitive process of trust formation has been shown to positively influence a person's intention to use e-commerce Web sites [28, 29, 58, 90]. Recently, researchers have shown that this trust formation process holds even when an IT artifact, rather than a business or organization, is the object of trust $[46,50,86]$. In these studies, it was found that people form trusting beliefs toward IT artifacts (i.e., whether or not people perceived the IT artifact to possess dependable/useful characteristics). These trusting beliefs then strongly predicted trusting intentions (i.e., whether or not people were willing to depend on the IT artifact). Consistent with these findings, our first hypothesis is as follows: 
Hypothesis 1: Trusting beliefs in the IT artifact will positively affect intention to use.

\section{Institution-Based Trust and Trust in IT Artifacts}

Another important element of trust is institution-based trust-a person's feeling or belief that the environment in which he or she transacts has appropriate safeguards and protections $[32,58]$. McKnight et al. define two dimensions of institution-based trust-namely, structural assurance, the belief that "structures are in place to promote success" [58, p. 339], and situational normality, the belief that "the environment is in proper order and success is likely because the situation is normal and favourable" [58, p. 339].

McKnight et al. [60] theorized that institution-based trust significantly affects both trusting beliefs and trusting intentions. Several recent studies have found that institution-based trust can strongly influence trust in online environments [3, 64, 66]. McKnight et al. [58] suggest that consumers' perceptions of high situational normality contribute to trust placed in online vendors. However, despite its formative role, little IS research has examined institution-based trust. Gefen et al. [32] recently called for IS research to include institution-based trust in our models, specifically as it relates to the IT artifact.

Regarding its role in trust formation, theorists have explained that components of institution-based trust—structural characteristics of safety and security-are just some of the many cues that people use when determining whether to place trust in another party [28]. In online contexts where other cues are available, such as peer endorsement [49] or recommendation agents $[46,86]$, institution-based trust may be less salient. However, in e-commerce settings where available cues are minimal and people chiefly transact with new or unknown entities, the role of institution-based trust becomes much more important [32]. In such cases, users take into account the structural characteristics and normality of the environment to counterbalance the lack of cues needed to form trusting beliefs in an online service. We therefore hypothesize that a person's perception of institution-based trust in the Internet will positively affect his or her trusting beliefs in the IT artifact.

Hypothesis 2: Institution-based trust will positively affect trusting beliefs in the IT artifact.

\section{Ease of Use Linked to Trust}

We further hypothesize that greater perceived EOU will correspond to higher levels of trusting beliefs. This hypothesis is consistent with the integrated trust-technology acceptance model advanced by Gefen et al. [29], who found strong evidence that EOU leads to higher levels of trust. More recently, Wang and Benbasat [86] also found strong support for this relationship. The logic for this relationship is that in the absence of better information, people use available information such as appearance 
as a heuristic to judge trustworthiness [6]. Gefen et al. [29] observe that perceived EOU should also increase trust through the perception that the e-commerce vendor is investing in the relationship, and, in so doing, signals a commitment to the business relationship. We formalize this hypothesis as

Hypothesis 3: Perceived EOU will positively affect trusting beliefs in the IT artifact.

\section{System Quality}

In order to identify relevant formative subconstructs that map well to the construct of trust in the IT artifact [8], this research incorporates constructs from system quality literature. System quality is a major component of the DeLone and McLean model for IS success and later respecifications $[16,76]$. However, research examining system quality and its components has been sparse over the last decade [62]. An exception is literature on Web site quality, which has developed into an active research stream $[19,52]$. Seddon defines system quality as "whether or not there are 'bugs' in the system, the consistency of the user interface, ease of use, quality of documentation, and sometimes, quality and maintainability of the program code" [76, p. 246].

\section{System Quality and Trust}

System quality attributes are relevant to the concept of trust because recent research suggests that technical aspects of IT artifacts affect users' willingness to trust [32]. For instance, McKnight et al. [59] found site quality to be a stronger predictor of trusting beliefs $(0.51)$ than either reputation (0.39) or structural assurance of the Web (0.10).

However, beyond this recognition of a link between quality and trust, prior Web site quality research only tacitly includes the concept of trust. In two extensive and independent literature reviews of Web site quality, both Field et al. [19] and Wolfinbarger and Gilly [89] show that risk and security are major components of a plurality of Web site quality studies. One can argue that because security and risk are closely related to trust $[10,18,65,74]$, trust is, in fact, a tacit component of many Web site quality studies. This tacit accordance with trust research makes Web site quality especially relevant and viable for integration into conceptual trust models.

\section{Web Site Quality/User Interface Measures}

In their extensive review of system quality in IS research, Nelson et al. identified two IT domains requiring further investigation of relevant system quality constructs: "Web-based applications and mobile Internet services" [62, p. 220]. Accordingly, we selected two system quality constructs that should strongly relate to trust in mobile commerce technologies—navigational structure and visual appeal [61]. Each of these attributes is highly cited in m-commerce literature and relates well to the technological qualities identified above as likely affecting trust in the IT artifact. 


\section{Navigational Structure}

Navigational structure is defined as "the organization and hierarchical layout of the content and pages in a Website" [61, p. 449] and involves the relative effort required for a user to traverse an IT artifact user interface [52]. Navigational structure is a common component of many Web site quality studies [52, 53, 61, 89].

Although navigational structure is related to EOU, both are distinct concepts. Nelson et al. note that system quality constructs are often equated with EOU because "ease of use may be a consequence of system quality" [62, p. 205]. However, they stress that these constructs are "not the same" [62, p. 205]. In our case, while EOU reflects a user's overall perception of the usability of interacting with an IT artifact, navigational structure is specific to how logically or intuitively information is arranged within an $\mathrm{m}$-commerce site. Nelson et al. note that navigational structure is especially vital in mobile commerce sites because of limited screen space. In studies of m-commerce, navigational structure is frequently cited by users as being crucial $[47,77]$.

\section{Visual Appeal}

Visual appeal is another commonly cited Web site quality attribute for online Web sites $[19,52,53,61,89]$. Visual appeal is defined as "the tangible aspect of the online environment that reflects the 'look and feel' or perceived attractiveness of a Website" [61, p. 450]. Visual appeal connotes the attractiveness of the Web site, including graphics, colors, and fonts [52, 53]. These general aesthetics can be an important determinant of "surface credibility," the extent to which "a perceiver believes someone or something based on simple inspection" [84, p. 42]. Tseng and Fogg explain that

with surface credibility, people are judging a book by its cover. In the world of human relationships, we make credibility judgments of this type nearly automatically. The way people dress or the language they use immediately influences our perception of their credibility. The same holds true for computer systems and applications. For example, a Web page may appear credible just because of its visual design. [84, p. 42]

Kim and Moon [43] found that visual elements, such as layout and color selection, affected users' perception of the trustworthiness of the Web site.

\section{Relationship Between System Quality and Ease of Use}

System quality and EOU are commonly associated in IS research. In fact, Nelson et al. observe that often "ease of use may be a consequence of system quality" [62, p. 205]. Wixom and Todd [88] also associate system quality with EOU, albeit indirectly. In their theoretical integration of user satisfaction and technology acceptance literature, Wixom and Todd [88] draw on attitude literature to show how users' beliefs about the quality of a system lead to attitudes of satisfaction, which in turn lead to system usage behaviors. In their model, system quality and satisfaction are object-based attitudes 
that "influence the beliefs a person holds or the relative importance he attaches to attitudinal and normative considerations" [1, p. 9]. Thus, attitudes about system quality and satisfaction affect beliefs of EOU and later intention to adopt the system.

Wixom and Todd [88] used satisfaction as a mediating variable between the constructs of system quality and EOU, relying on the correspondence principle [20], which states that beliefs and attitudes that are nearest to the behavior of interest will be the most significant predictors of that behavior. As theorized, Wixom and Todd [88] found satisfaction to be the most important predictor of EOU, but they also found that system quality had a significant direct effect on EOU (path $=0.66, R^{2}=0.55$ ). Accordingly, we predict the relationship between system quality attributes of navigational structure and visual appeal and EOU as follows:

Hypothesis 4a: Navigational structure perceptions will positively affect perceived EOU.

Hypothesis 4b: Visual appeal perceptions will positively affect perceived EOU.

\section{Relationship Between System Quality and Trusting Beliefs}

In addition to the mediated effect of navigational structure and visual appeal on trusting beliefs through EOU, we also hypothesize that these constructs will have a direct effect on trusting beliefs. Several researchers have pointed to good user interface design as a means of building trust in an IT artifact [57]. Bart et al. [4] found that navigability and graphical presentation are important drivers for consumer trust in a Web site and urged managers to "go beyond privacy and security and focus on factors such as navigation and presentation" [4, p. 148]. Moreover, Bart el al. [4] found that both navigation and presentation, along with other Web site quality measures, were more significant predictors of consumer trust in a Web site than privacy and security features.

Consistent with the above findings, we hypothesize that navigational structure and visual appeal will directly affect trusting beliefs in the IT artifact. During the trust formation process, people observe available cues to form trusting beliefs [32]. In online environments such as mobile commerce where available cues are limited, system quality attributes such as visual aesthetics can strongly influence the formation of trusting beliefs and, indirectly, trusting intentions and behaviors. McKnight observes:

Trust in technology is built the same way as trust in people. When users first experience technology, signals of well-done user interfaces and good vendor reputations will build trust. Reliable, dependable, quality IT performance is the key over time.... The entire system infrastructure should demonstrate quality. [57, p. 330]

Accordingly, we hypothesize that navigational structure and visual appeal will influence trusting beliefs as follows:

Hypothesis 5a: Navigational structure perceptions will positively affect trusting beliefs in the IT artifact. 
Hypothesis 5b: Visual appeal perceptions will positively affect trusting beliefs in the IT artifact.

\section{Trust and Culture}

An important gap in our understanding of trust in IT artifacts is the influence of ethnic or national culture on user willingness to trust an IT artifact. In their review of system quality literature, Nelson et al. note that "non-technical characteristics, such as task type or user demographics, may play important roles in understanding quality" [62, p. 220]. Moreover, in their extensive review of culture in IS literature, Leidner and Kayworth [48] found that national culture significantly affects the development, implementation, adoption, usage, and management of IS. Across these IS domains, national culture was shown to substantively influence how successfully IS were integrated into organizations. Despite these insights, the influence of ethnic or national culture on user willingness to trust an IT artifact is not yet fully investigated. Accordingly, we investigate both culture's direct effect on trust in an IT artifact and its moderating effect on the relative salience of design attributes described previously.

\section{Direct Effect of Culture on Trust in IT Artifacts}

Culture directly affects trust in artifacts in relation to technology adoption. Trust in the IT artifact has been shown to be closely related to IT adoption [86]. Moreover, much of the cross-cultural IT adoption literature involves trust (or distrust) as a point of differentiation, using Hofstede's cultural value of uncertainty avoidance, which is "the degree to which members of a society feel uncomfortable with uncertainty and ambiguity" [37, p. 83]. This uncertainty avoidance measure is risk based, and has been shown to be closely related to the construct of trust [17]. In Leidner and Kayworth's review [48], nine out of 15 studies found convincing evidence for this relationship. The reasoning for this choice is that the adoption of new IT involves risk, and, therefore, new IT should be less readily adopted in cultures with a low tolerance for risk. For example, Thatcher et al. [83] showed how people of countries with high levels of uncertainty avoidance were less willing to experiment with and adopt new technology. Srite and Karahanna [78] found that high uncertainty avoidance individuals are more influenced by their social norms to determine whether or not they should use the technology than are low uncertainty avoidance individuals. Similar effects on IS research models were found by Hasan et al. [35], Jarvenpaa and Leidner [40], Png et al. [69], Straub [80], and Straub et al. [81]. The literature is thus highly suggestive that individuals from uncertainty avoidance cultures will tend to place less trust in the IT artifact. We therefore posit:

Hypothesis 6: Individuals from high uncertainty avoidance cultures will place less trust in the IT artifact than will individuals from low uncertainty avoidance cultures. 


\section{Moderating Effect of Culture on Trust in IT Artifacts}

Multiple cross-cultural studies have shown that various cultures exhibit different preferences in the design of IT artifacts. For example, Cyr et al. showed that aspects of Web site design such as navigability, layout, and graphical elements were preferred differently across Japanese, Canadian, U.S., and German cultures [13]. Del Galdo and Nielsen [15] and Marcus and Gould [55] found similar results. Because culture may affect the relative importance of Web site design characteristics to a consumer, we expect culture to influence the extent to which system quality design elements contribute to user trust in an IT artifact.

Given the effect of national culture on the preference for design elements, we offer the following exploratory hypotheses in relation to culture and system quality attributes of IT artifacts:

Hypothesis 7a: Navigational structure perceptions will positively affect trusting beliefs in the IT artifact less for individuals from high uncertainty avoidance cultures than for individuals from low uncertainty avoidance cultures.

Hypothesis 7b: Visual appeal perceptions will positively affect trusting beliefs in the IT artifact less for individuals from high uncertainty avoidance cultures than for individuals from low uncertainty avoidance cultures.

\section{Research Design}

\section{Choice of M-Commerce Portals as Research Stimulus}

TO EXAMINE TRUST PLACED IN THE IT ARTIFACT, we chose m-commerce portals (viewable by the Internet-enabled mobile devices) as the IT artifact of interest. This technology is an especially good choice for issues relating to trust in IT artifacts for several reasons. First, trust issues are on the forefront when users adopt new technologies [23, 24] or participate in new modes of commerce, such as e-commerce $[25,29,58]$. Both of these points are equally true of m-commerce portals, Web- or client-server-based storefronts designed to make e-commerce services accessible for mobile devices [34, 77, 85]. Just as e-commerce has made trust issues in IS especially prominent in recent years [32], we also expect m-commerce to raise the awareness of trust issues as consumers begin to purchase through the unfamiliar method of using an m-commerce phone, PDA, or other enhanced mobile device and as consumers are persuaded to rely on the relatively new technology of m-commerce [57]. This point has been made especially poignant with the introduction of Apple's iPhone. Thus, by selecting m-commerce portals, we expect trust-related issues to be more salient than might otherwise be the case with other IT artifacts.

Second, because of the small-form factor of m-commerce devices, screen space is much more limited vis-à-vis a computer workstation. This presents fewer surrogate cues to the user for human interaction than would be available with full-scale PC-sized images, multimedia, or recommendation agents. In the absence of human-centric trust 
attributes such as integrity, benevolence, and trust [86, 87], users are forced to form trusting beliefs based on attributes of the m-commerce portal itself [50,57]. Thus, we expect the use of $\mathrm{m}$-commerce portals to show stronger relationships between system quality attributes and the formation of trust in the IT artifact.

Third, because m-commerce is rapidly gaining importance in many areas of the world [73], it is advantageous to recognize and understand how trust issues are applicable to m-commerce portals. Finally, to our knowledge, no study has attempted to examine trust issues specific to m-commerce. Therefore, an understanding of how trust in $\mathrm{m}$-commerce portals can be increased both fills an important gap in our literature and provides practitioners valuable information for the design of $\mathrm{m}$-commerce portals.

\section{Two Disparate Cultures Relative to Trust: United States and France}

To see how culture may have a particular bearing on trust in IT artifacts, our study was conducted in research sites in the United States and France. These countries were selected because of the large difference between the United States and France in trusting beliefs. As profitably applied to IS research [24], Fukuyama [23] presents historical analysis that France is a low-trust society and the United States is a hightrust society [31]. Hofstede's findings [36] likewise show a gap between France and the United States on uncertainty avoidance (France, 86; United States, 46), which is an indicator of a society's tolerance for risk [17].

The more recent cross-cultural global leadership and organizational behavior effectiveness (GLOBE) study by House et al. [38] found a similar difference in uncertainty avoidance. In their analysis of 17,300 managers in 62 cultures, House et al. [38] examined uncertainty avoidance in terms of both cultural practices and cultural values. France was found to exhibit higher uncertainty avoidance in terms of both cultural practices (France, 4.43; United States, 4.15) and cultural values (France, 4.26; United States, 4.00). Inferring from this data, a likely difference in trust between France and the United States might be smaller than in Hofstede's study, but the difference would still be significant in that France exhibits higher uncertainty avoidance than does the United States. Given the agreement among these cultural analyses in the likely gap in trusting values between France and the United States, we chose these two research sites to embody these differences in cultural values for trust.

\section{Instrumentation, Experimental Procedures, and Sampling}

Experimental treatments were administered in France and the United States to provide a contrast between cultures. Each subject was given a pretest based on McKnight et al.'s [58] trust measures to gauge the participant's attitudes toward institution-based trust, both in general and specifically in relation to online commerce. Next, a free simulation experiment was administered depicting the use of an Internet-enabled mobile phone to perform a mobile commerce transaction. The free simulation consisted of a series of mobile phone screenshots showing each step in the purchase process of an actual mobile commerce Web site (see Figure 2). Finally, a posttest (consisting of measures 

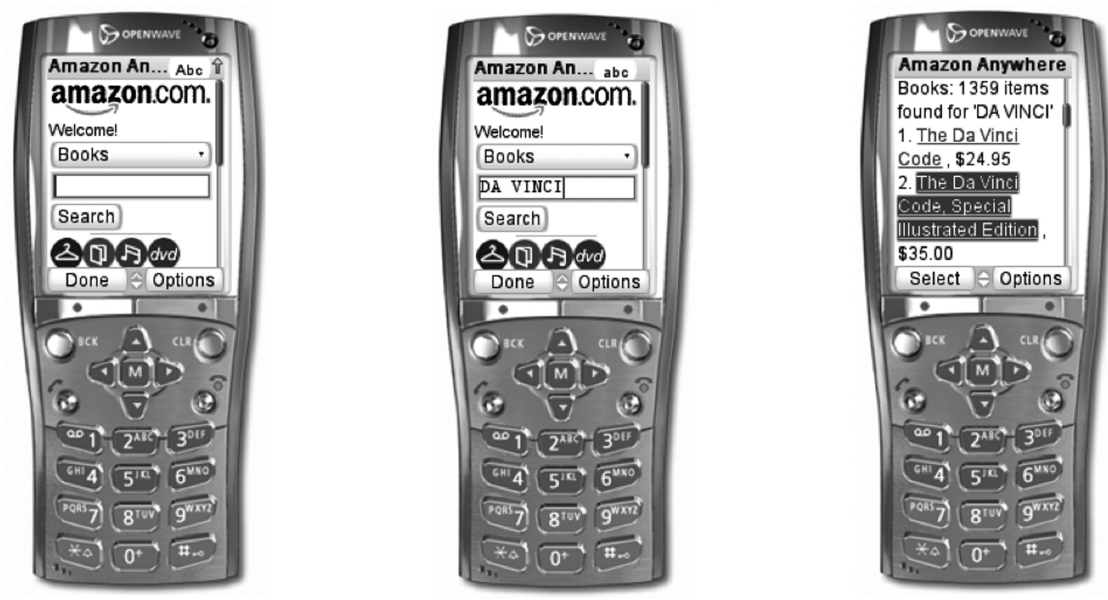

Figure 2. Screenshots of Amazon Anywhere, M-Commerce Site

from McKnight et al. [58], Montoya-Weiss et al. [61], and Wang and Benbasat [86]) was used to measure system quality attributes of the user interface, the level of trust that each participant placed in the simulated IT artifact, and user intentions to adopt the m-commerce portal as a means of purchasing.

To test the hypotheses, a free simulation experimental design was implemented, as noted above $[22,27]$. In free simulation experiments, treatment levels are not predetermined. Rather, levels range freely in accordance with how participants interact naturally with the simulation. The simulation consisted of a set of 12 sequential screenshots that depicted each step of the purchase process for an m-commerce portal using a cellular phone. Amazon.com's "Amazon Anywhere" service (www.amazon. com/mcommerce) was chosen as the m-commerce portal because of its high brand profile both in the United States and in Europe. Furthermore, the use of an operational $\mathrm{m}$-commerce portal contributed to the realism of the simulation. Choosing a highprofile brand helped to ensure that participants from both countries recognized the $\mathrm{m}$-commerce seller. This better allowed us to look for differences in the perceptions of French and U.S. subjects in similar settings.

After completing the pretest, participants viewed a numbered sequence of screenshots showing each step of the Amazon Anywhere m-commerce portal purchase process (see Figure 2). The Amazon Anywhere portal is an m-commerce storefront for Amazon. com's retail offerings. Specifically designed for viewing using a small screen, the Amazon Anywhere portal interface provides links to Amazon's most popular product categories as well as a simple search. The interface is designed so that it is easily navigable using the keypad of a mobile device.

In the simulated purchase process, participants viewed the steps required to search for a particular book and then select an item based on the search results. Search results displayed thumbnail images for each matching item, along with a link to more 
information. Once a book is selected, Amazon Anywhere provides a streamlined purchase process in which a user logs into an existing Amazon account and then pays using a preselected payment method. Shipping details are similarly specified beforehand. Thus, the Amazon Anywhere portal offers a streamlined storefront to Amazon. com specifically suited for browsing and purchasing on a mobile device. The entire purchasing process from start to finish was captured in a series of screenshots and reproduced in color copies. ${ }^{1}$

Because each participant had his or her own set of screenshots, participants viewed the screenshots independently from other participants. In addition, participants were not restricted from reviewing previously examined screenshots. This lack of procedural controls is consistent with the design of a free simulation experiment, which allows participants to interact with the simulation in an unrestricted manner.

Once they had viewed the screenshots, participants took a posttest based on measures used by Wang and Benbasat [86]. This posttest, based on the measures of McKnight et al. [58], was specifically designed to gauge participant levels of trust in an IT artifact. However, because Wang and Benbasat [86] were measuring a different form of IT artifact (that is, Web-based recommendation agents), minor changes were made to adapt the posttest measures to $\mathrm{m}$-commerce portals. The posttest also included system quality measures from Montoya-Weiss et al. [61] for navigational structure and visual appeal. Attached to the posttest was a short demographical questionnaire to allow for the comparison of control data between research sites.

\section{Participant Recruitment}

The experiments were conducted at two major universities-one at Georgia State University, Atlanta, Georgia, and the other at Université Paris-Dauphine, Paris, France. Participants were recruited from MBA and other graduate-level business courses at both research sites. One of the researchers visited student courses to administer the experiment. A total of 116 participants took part in the study in France and 135 participants took part in the United States.

Participants were not offered rewards for taking part in the study; however, nearly all students in the classes visited chose to volunteer and participate rather than take a break or complete an alternative activity. While offering extrinsic rewards is common in business research, several researchers suggest that incentives are negatively related to the intrinsic interest and motivation of students $[44,45]$. There is no consensus on this point, but we believe that offering alternative activities helped to ensure that only motivated students took part in the study.

\section{Data Analysis}

FOR DATA ANALYSIS, WE USED SmartPLS 2.0 [72]. SmartPLS is a component-based path modeling software application based on the partial least squares (PSL) method. SmartPLS is comparable to PLS-Graph; it is based on the same method and offers similar features with an improved graphical interface. While covariance-based software such 
as LISREL is mainly designed to perform analyses involving reflective constructs, PLS-based applications such as SmartPLS or PLS-Graph can readily handle both reflective and formative constructs [30]. Therefore, we felt SmartPLS was appropriate in that the model includes both reflective and formative constructs. Marcoulides and Saunders [54] critiqued studies that use PLS with insufficient sample sizes and so we were cognizant of the need for sufficiently large groups of subjects.

\section{Measurement Validation}

The first stage in data analysis should evaluate the measurement properties of the instrumentation. Typical analyses include reliability and convergent/discriminant validity. Given the presence of both formative and reflective constructs in our model, we implemented measures consistent with the nature of the constructs. Analyses suitable for reflective constructs do not apply to formative ones [7, 30, 79]. Validation of reflective constructs is well documented in the literature [68], but there is still little guidance for validating formative constructs. We therefore relied upon prior studies that used formative constructs and still assessed the measurement properties. Table 1 shows details of constructs and measures subjected to instrument validation. Table 2 details the individual measurement items of the instrument.

\section{Validation of Reflective Constructs and Subconstructs}

Consistent with Wang and Benbasat [86], we modeled trust as a second-order construct. Our conceptualization of trust follows McKnight et al. [59] and so includes three subdimensions-competence, benevolence, and integrity. Following the guidelines provided by Jarvis et al. [41], we modeled trust as a second-order formative construct. Indeed, we believe trust is better defined as a formative construct than a reflective one. While Wang and Benbasat seem to acknowledge the formative nature of trust [86], they decided to model it as a second-order reflective construct because measures were found to correlate highly [59]. Furthermore, they found no significant differences in path coefficient significance depending on the choice of modeling the trust construct as formative or reflective.

However, because modeling formative constructs as reflective ones can lead to specification errors and heightened levels of Type I and II errors [68], we decided to model trust as a second-order formative construct. Similarly, as shown in Table 1, we modeled institution-based trust as a second-order formative construct. We used preexisting measures with a seven-point Likert scale ranging from "strongly disagree to "strongly agree" (refer to the online appendices for instrumentation details; http:// anthonyvance.com/appendices/Trust-JMIS-2008.pdf). We first analyzed measurement properties of the reflective construct and subconstructs of the instrument. Then we replaced first-order reflective constructs with their latent variable scores given in SmartPLS, as suggested by Wang and Benbasat [86]. This allowed us to test for the 


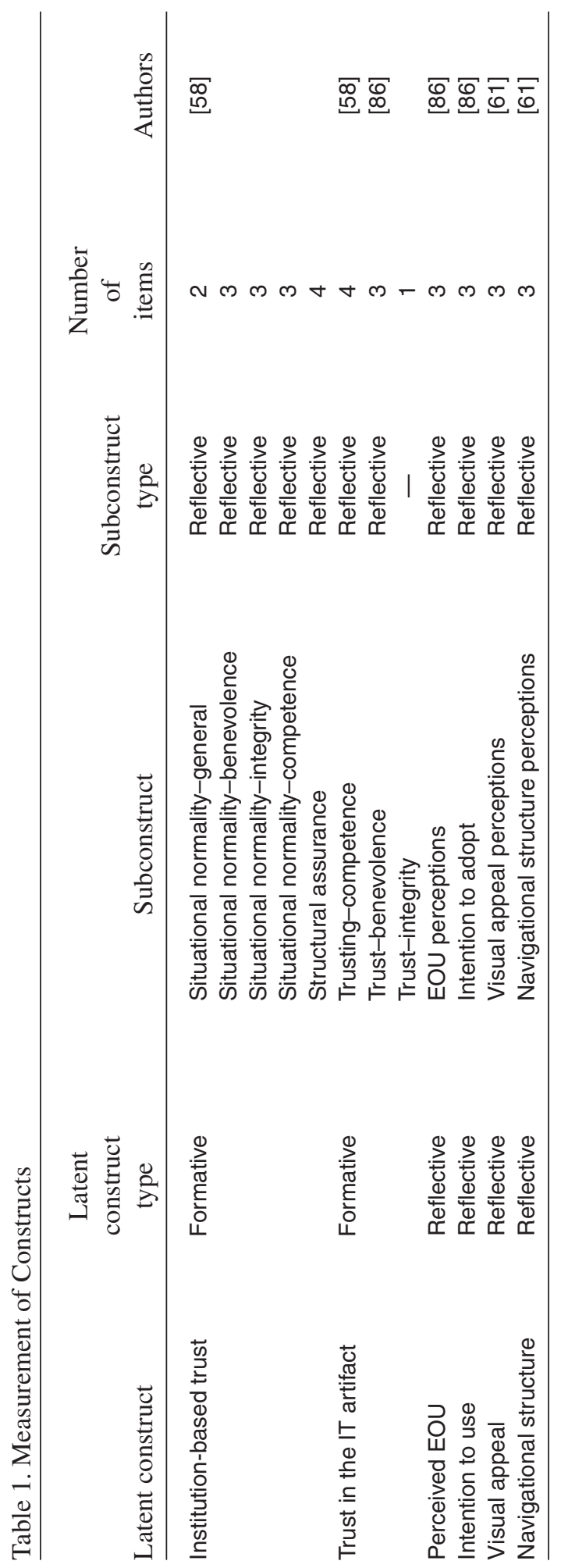




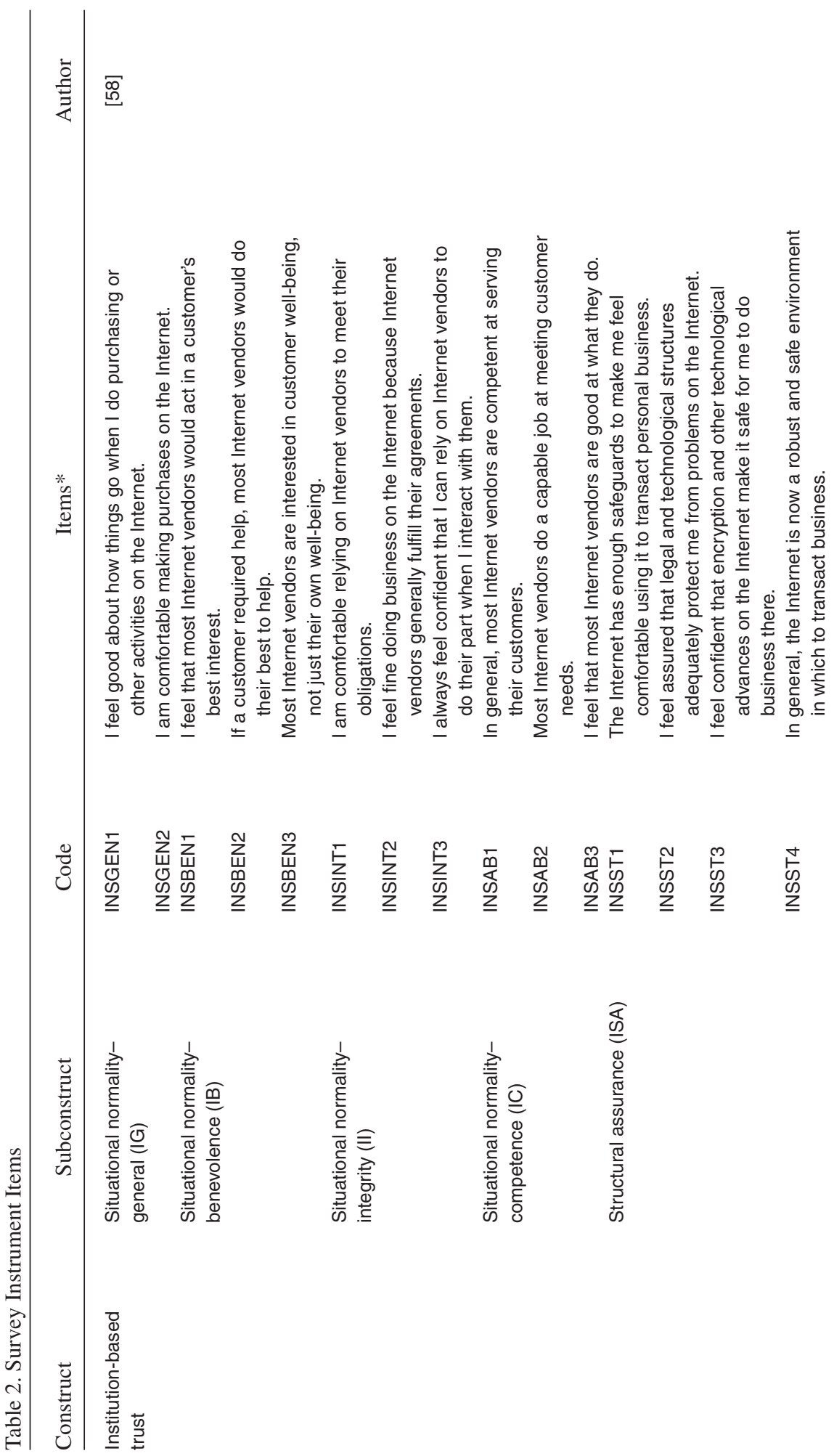


盢

$\underset{\Phi}{\mathscr{D}}$

$\underset{\Phi}{\Phi}$

효

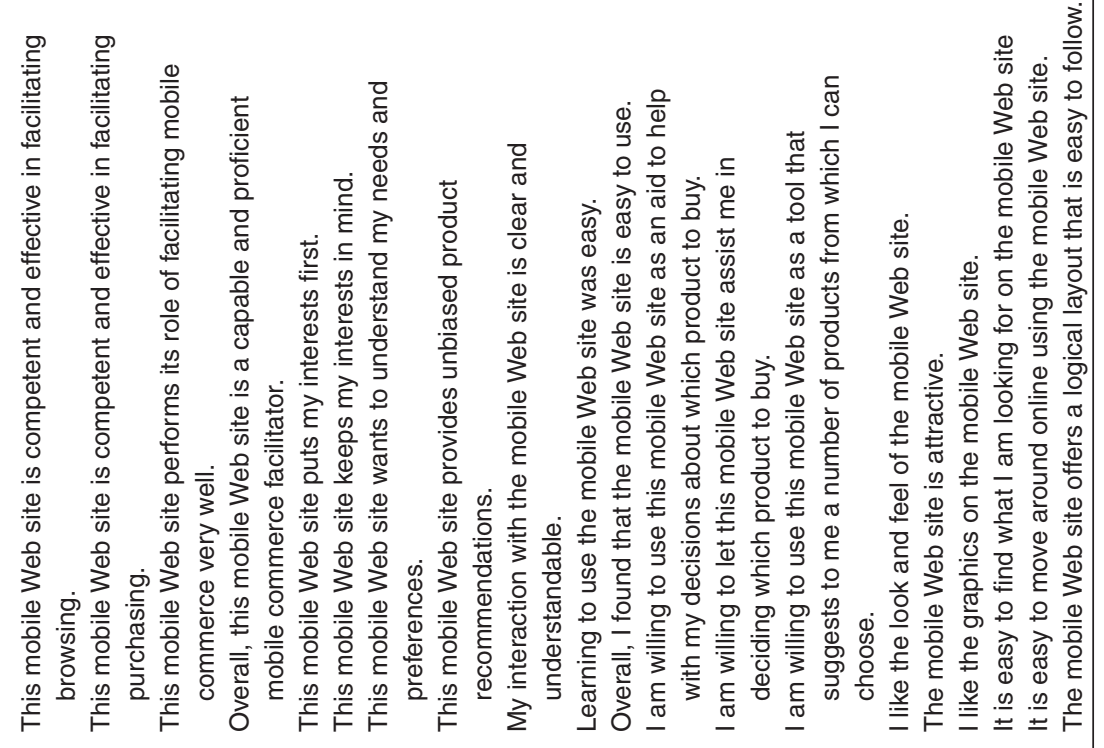

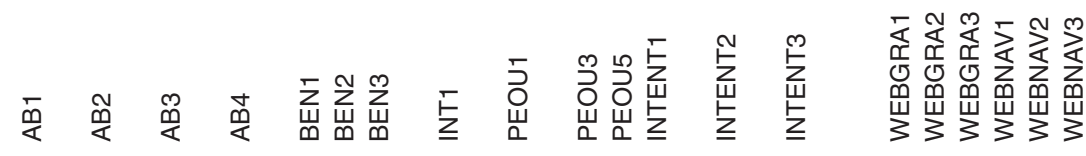

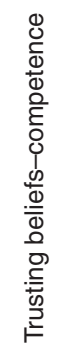

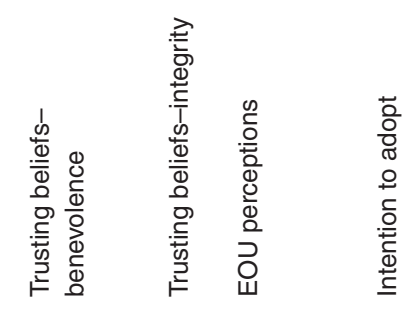

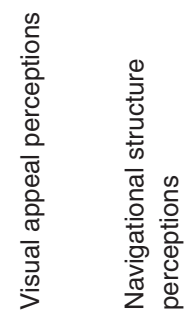

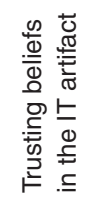

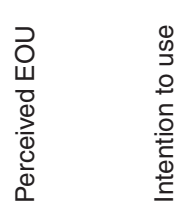

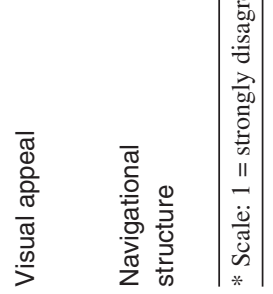


validity of second-order formative constructs and the analysis of the structural paths. Internal consistency of subconstructs was assessed via Cronbach's alphas. These were calculated for both the U.S. and French samples, as well as for the overall sample. Most values were above 0.80 , and all were greater than the accepted threshold of 0.70 recommended in the literature [63]. Overall, these results indicate acceptable measurement properties for all reflective constructs.

Discriminant validity can be assessed when items of one particular construct correlate poorly with items of all other constructs while correlating highly with their own construct. In order to assess discriminant validity of reflective constructs and subconstructs, we examined factor and cross-loadings, and the average variance extracted (AVE) matrix. The factor structure shows that the items load higher on their intended construct than on any other construct. ${ }^{2}$ Moreover, they load together with very high values. While some items also load reasonably high on unintended constructs, most of these values are below the 0.60 recommended cutoff [21]. Therefore, we can conclude that the reflective constructs differ.

Internal consistency was assessed by composite reliability and Cronbach's alphas. ${ }^{3}$ With values ranging from 0.80 to 0.95 for composite reliability and from 0.77 to 0.90 for all Cronbach's alphas but one (at 0.63 for institution-based trust-benevolence), we can conclude that the scales are reliable.

\section{Validation of Formative Constructs}

This study had two formative constructs. These constructs are institution-based trust and trust in the IT artifact. Because of the nature of formative constructs, different analyses need to be conducted for testing reliability and validity. In order to assess convergent and discriminant validity for these constructs, we employed the modified multitrait-multimethod (MTMM) technique described by Loch et al. [51]. ${ }^{4}$ Suffice it to say that the tests followed the recommended procedures in Loch et al. [51] and examination of the modified MTMM indicates that the instrument has acceptable measurement properties. Both convergent and discriminant validity were demonstrated in our analyses.

\section{Common Methods Variance}

To test for common methods variance (CMV), we first conducted Harman's singlefactor test [70]. Podsakoff et al. argue that if there is a detrimental level of common method bias, "(a) a single factor will emerge from exploratory factor analysis (unrotated) or (b) one general factor will account for the majority of the covariance among the measures" [70, p. 889]. Because more than one factor emerged to explain the variance in our analysis, we infer that common methods bias in this case is not high. The second test was to examine a control for the effects of an unmeasured latent methods factor [70, p. 891]. In this analysis, of the 23 paths from CMV to single-indicator constructs, only seven were significant, indicating a relatively small amount of CMV. ${ }^{5}$ 


\section{Hypothesis Testing}

After assessing measurement properties and CMV of the instrument, we tested our hypotheses through the PLS structural model (see Figure 3). The sample consisted of 136 U.S. and 116 French business students. In order to analyze the influence of culture, we coded culture as a binary variable with the value of 0 for the U.S. subsample, and 1 for the French subsample. As suggested above, subjects from the French subsample are considered to be more uncertainty avoidant than subjects of the U.S. subsample. Such an analysis could be criticized for not directly measuring the levels of uncertainty avoidance. However, we relied on previous work that indicates that Hofstede's detected differences still exist between France and the United States, although possibly at a lower level $[39,42,81]$. We measured culture in our study in a way consistent with many other studies involving the effects of culture, which are largely based on Hofstede, and which consider culture at the nation-state level [48, 78, 82]. Other competing conceptualizations suggest a value-based approach of culture at an individual level [78]. Another conceptualization is that of Leidner and Kayworth [48], who develop a model integrating values, IT, and conflict and offer an approach for dealing with both national and organizational culture.

The average age in the U.S. sample was 31.6 and 22.8 in the French sample. ${ }^{6}$ Also, the American subjects spent an average of 6.3 years in college studies as compared to 4.4 years for the French subjects. In order to control those parameters, we first included them as control variables in the analysis. Because we found no significant effect of age or of time spent in college studies on the model, we later dropped them from the analyses of hypotheses. Regarding the nationality of participants, subjects in the French university were mostly French citizens, and subjects in the U.S. university were mostly American citizens, thus implying some homogeneity in our sample at the national-culture level.

\section{Evaluating Moderating Effects}

Testing moderating effects involves comparing a "main effect" model and a moderating effect model $[9,11]$ and meeting nine conditions that indicate that no errors of commission have been made. Our detailed analysis concludes that we have no errors of commission. ${ }^{7}$ The interaction terms were calculated by multiplying the moderator (culture) by the predictor variables (navigational structure and visual appeal). The moderating effects model included these interaction variables, while the main effects model did not. However, because the moderating effect of culture on the influence of visual appeal on trusting beliefs in the IT artifact (TRUST) was insignificant, we decided to test only for the effect of the interaction of navigational structure with culture. The $R^{2}$ of TRUST for the main effect model was $R^{2}=0.471$. When including the interaction term, the $R^{2}$ for TRUST is 0.488 . We then calculated the effect size applying the following formula suggested by Cohen [12], as in Chin et al. [11]: $F^{2}=\left[R^{2}\right.$ (interaction model) $-R^{2}$ (main effect model) $] /\left[1-R^{2}\right.$ (main effect model) $]$. We thus obtained an effect size $\left(F^{2}\right)$ of 0.03 . Then, we multiplied $F^{2}$ by $(n-k-1)$, 


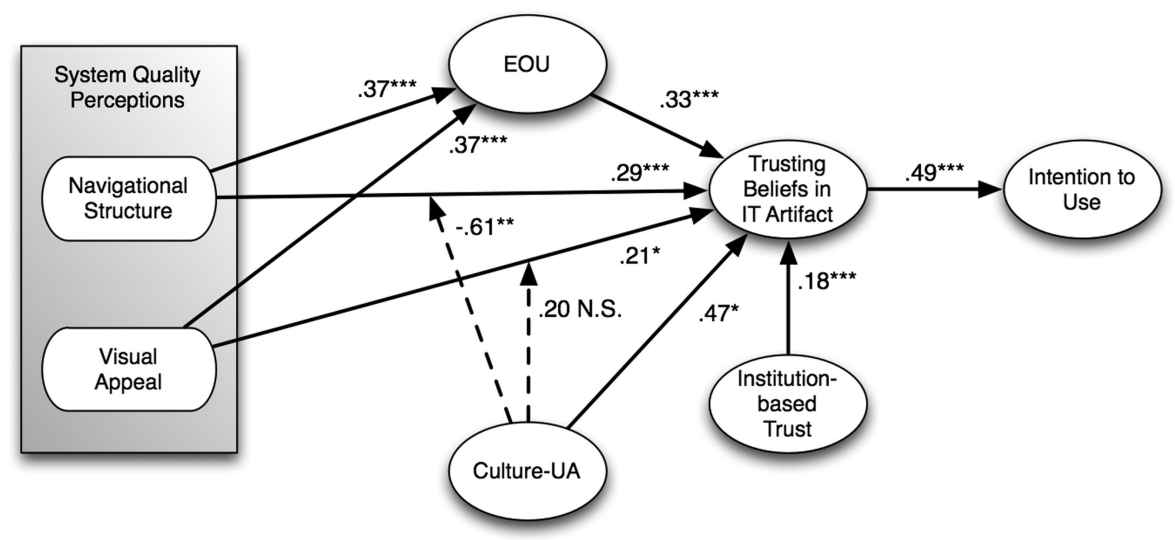

Figure 3. Research Model Showing the Significance of Relationships

Notes: $\mathrm{EOU}=$ ease of use; $\mathrm{UA}=$ uncertainty avoidance. $* * p<0.01 ; * * * p<0.005$.

where $n$ equals sample size (251) and $k$ equals the number of independent variables (4). This enabled us to conduct a pseudo $F$-test for the change in the $R^{2}$ with 1 and $n-k$ degrees of freedom, similarly to Mathieson et al. [56]. The result of the pseudo $F$-test was $7.90(p<0.005)$. An effect size of 0.02 is small, 0.15 is moderate, and 0.35 is large [12]. Therefore we can conclude that the effect size for culture in our model is small $(0.03)$ yet significant.

Positing that institution-based trust will positively affect trust in the IT artifact, H1 was supported. $\mathrm{H} 4 \mathrm{a}$, hypothesizing that navigational structure positively influences perceived EOU, is strongly supported $(\beta=0.37, p<0.005)$. Similarly, $\mathrm{H} 4 \mathrm{~b}$, which states that visual appeal positively affects perceived EOU, is also well supported $(\beta=$ $0.37, p<0.005)$. Our study therefore provides support for the influence of system quality on perceived EOU. H5a, positing that navigational structure positively influences trust, is supported $(\beta=0.29, p<0.005)$, and $\mathrm{H} 5 \mathrm{~b}$, proposing that visual appeal positively influences trust, is also supported $(\beta=0.21, p<0.025)$. H3, which states that perceived EOU is positively related with trust, is likewise strongly supported $(\beta=0.33, p<0.005)$, as shown in prior studies $[29,86]$. Consistent with prior studies [11], H1, which states that trust will positively affect intended use, was also strongly supported $(\beta=0.49, p<0.005)$.

Regarding the influence of culture in our model, two of our hypotheses were validated. H6, which argues that culture influences trust, is supported $(\beta=0.47, p<$ 0.025 ). As posited, French people, who have long been said to be more uncertainty avoidant than American people, had less propensity to trust in the IT artifact. Stating that culture has a moderating effect on the relation between navigational structure and trust, $\mathrm{H} 7 \mathrm{a}$ was supported $(\beta=-0.61, p<0.01)$, and $\mathrm{H} 7 \mathrm{~b}$, stating the moderating effect of culture on the relation between visual appeal and trust, was not.

Explained variance in our model was substantial with 49.2 percent of the variance in IT trust explained by antecedents and 24.4 percent of intention to use explained by trust in the IT artifact. 
Table 3. Results of Hypotheses Tests

\begin{tabular}{llc} 
Hypothesis & Supported? \\
\hline H1 $\quad \begin{array}{l}\text { Trusting beliefs in the IT artifact will positively affect intention } \\
\text { to use. }\end{array}$ & Yes \\
H2 $\quad \begin{array}{l}\text { Institution-based trust will positively affect trusting beliefs in } \\
\text { the IT artifact. }\end{array}$ & Yes \\
H3 $\quad \begin{array}{l}\text { Perceived EOU will positively affect trusting beliefs in the } \\
\text { IT artifact. }\end{array}$ & Yes \\
H4a $\quad \begin{array}{l}\text { Navigational structure perceptions will positively affect } \\
\text { perceived EOU. }\end{array}$ & Yes \\
H4b $\begin{array}{l}\text { Visual appeal perceptions will positively affect perceived EOU. } \\
\text { H5a Navigational structure perceptions will positively affect trusting } \\
\text { beliefs in the IT artifact. }\end{array}$ & Yes \\
H5b $\begin{array}{l}\text { Visual appeal perceptions will positively affect trusting beliefs } \\
\text { in the IT artifact. }\end{array}$ & Yes \\
H6 $\quad \begin{array}{l}\text { Individuals from high uncertainty avoidance cultures will place } \\
\text { less trust in the IT artifact than will individuals from low uncertainty } \\
\text { avoidance cultures. }\end{array}$ & Yes \\
H7a $\quad \begin{array}{l}\text { Navigational structure perceptions will positively affect trusting } \\
\text { beliefs in the IT artifact less for individuals from high uncertainty } \\
\text { avoidance cultures than for individuals from low uncertainty } \\
\text { avoidance cultures. }\end{array}$ & Yes \\
H7b $\begin{array}{l}\text { Visual appeal perceptions will positively affect trusting beliefs } \\
\text { in the IT artifact less for individuals from high uncertainty } \\
\text { avoidance cultures than for individuals from low uncertainty } \\
\text { avoidance cultures. }\end{array}$ & No \\
\end{tabular}

\section{Discussion}

THE RESULTS OF OUR ANALYSIS CONFIRM that the extent to which trust (or lack of trust) in the IT artifact manifests itself will likely affect users' intention to adopt the IT artifact (see Table 3). This result lends further support to prior literature that came to similar conclusions [86, p. 90]. However, beyond confirming prior research results in this nascent research area, this study elucidates several possible relevant antecedents to the conceptualization of trust in the IT artifact. Our results demonstrate that trust in the IT artifact is directly influenced by system quality characteristics - that is, navigational structure and visual appeal. This is an important conclusion because it identifies aspects of trust in the IT artifact that are unique and different from attributes related to trust in people. Thus, this research addresses the call for research in Wang and Benbasat to "examine whether the conceptualization of trust in IT artifacts should be extended to include other relevant beliefs" [86, p. 90]. Using these findings, researchers of trust in IT artifacts should be better able to conceptualize and model trust in IT artifacts. These results demonstrate to designers of IT artifacts that user trust placed in IT artifacts can be enhanced by giving proper consideration to design elements such as navigability and visual aesthetics. 
A related contribution of our study is the theoretical linkage between trust in IT artifacts and system quality streams of research. This research highlights several areas of overlap between both streams of research and offers empirical evidence that significant overlap between the two research streams may exist. Other system quality measures may likely be related to trust in the IT artifact. By leveraging system quality research already performed in marketing and IS, researchers of trust in IT artifacts may be able to advance knowledge in this domain much more rapidly than if research in trust in IT artifacts was performed in isolation.

Our results also show that culture can affect the degree to which users place trust in the IT artifact. The posited contrast between the low-trust French culture and the higher-trust U.S. culture proved out in our findings. This has important implications for researchers of trust in IT artifacts because it demonstrates that IT artifacts are not culturally neutral. Rather, individuals of different cultures may exhibit markedly different attitudes toward placing trust in an IT artifact, which may, in turn, translate into varying levels of intention to adopt the IT artifact. Therefore, researchers of trust in IT artifacts should be mindful of possible cultural interactions in their research, even if culture is not explicitly included in the research model. Furthermore, designers of IT artifacts may be advised to consider which cultures are most likely to use IT artifacts and make appropriate design decisions accordingly. Such an approach may engender trust in IT artifacts and lead to greater adoption of technologies involved.

Finally, our research contributes to research in $\mathrm{m}$-commerce because it demonstrates to researchers and practitioners alike that adoption of m-commerce can be increased by improving design aspects of m-commerce portals. Even simple details such as navigational structure, layout, and graphical elements, if properly designed, can enhance user trust in m-commerce portals and lead to greater adoption of m-commerce in general. Further, our research provides evidence that the acceptance of m-commerce portals has a cultural dimension that should not be ignored. Managers who intend to deploy $\mathrm{m}$-commerce devices in low-trust cultures may therefore consider taking extra measures to ensure that $\mathrm{m}$-commerce portals are best designed to engender trust in the context of that culture. The several important contributions of the current study are presented in Table 4.

\section{Limitations and Future Research}

SEVERAL Limitations of THIS STUdy SHould BE recognized. First, the use of the Amazon. com brand in the experiment may have increased reported levels of trust due to its high brand familiarity [4]. Thus, levels of trust placed in the m-commerce portal, as well as the strength of the relationships between variables in the model, might have been affected by Amazon's brand appeal. A comparative unknown brand treatment would have allowed us to control for the effect of brand appeal. However, we would argue that it is unlikely that either the directionality of those relationships or their significance was affected by this potential bias, and thus the added realism gained from using an operational m-commerce portal was a reasonable trade-off. 
Table 4. Research Contributions

\begin{tabular}{ll}
\hline Element of research & Contributions \\
\hline Trust in the IT artifact & $\begin{array}{l}\text { Adds to the presently sparse body of work that focuses } \\
\text { on this important perspective on trust in systems. } \\
\text { Enhances the standard model of trust leading to } \\
\text { intention to use systems by exploring the effect of two } \\
\text { key dimensions of system quality on trust in the IT } \\
\text { artifact; these dimensions are navigational structure } \\
\text { and visual appeal. } \\
\text { Shows that perceived EOU partially mediates the effect } \\
\text { of system quality constructs on trust in the IT artifact. } \\
\text { Considers the impact of low-trust versus high-trust } \\
\text { cultural values and predisposition to trust on trust in } \\
\text { the IT artifact. } \\
\text { Eerceived EOU }\end{array} \quad \begin{array}{l}\text { Examines the possible interaction or multiplying effects } \\
\text { of culture on elements of system quality and the } \\
\text { graphical user interface. } \\
\text { Embeds the study in m-commerce, specifically the }\end{array}$ \\
Moderating effects & $\begin{array}{l}\text { "smart" phone, a new technology that utilizes a } \\
\text { Web-based interface. }\end{array}$ \\
\hline Emerging technology &
\end{tabular}

Second, subjects interacted with color screenshots rather than with actual mobile devices, thus weakening external validity. In this case, we believe the screenshots were appropriate surrogates of real devices given that our system quality constructs of interest-navigational structure and visual appeal-are both visual in nature. Moreover, the use of screenshots depicting the flow of the m-commerce transaction helped to provide a uniform experience, lessening variance due to participants' varying competence with m-commerce portals and mobile devices in general.

Third, because our study used graduate business students as participants in the experiments, the results of this study might be thought to be less generalizable to other populations [33]. Whereas graduate students might be seen as the very consumers of both m-commerce technologies and of books we were seeking, there is a good argument that graduate business students are representative of those people who are most likely to adopt m-commerce relatively early. Nevertheless, we must acknowledge the possibility of this limitation to external validity and urge future research to consider other sites for gathering data, sites such as shopping malls.

Fourth, there is a possibility of common methods bias in that subjects were polled using the same instrumentation as to their trust beliefs and their intentions to use the technology. We tested for this effect and did not find it to be present, but common methods bias is always a potential problem. Stronger designs would gather the dependent variable several weeks after the stimulation, a condition that we were not able to implement in this study. Many trust studies share this same limitation, however, and 
so there is some small measure of defense in having this weakness in common with the bulk of the trust literature.

Last, we investigated culture via France and the United States, which the literature indicates are low-trust and high-trust cultures, respectively. We know that direct measures of cultural values are highly desirable and future research in this domain should consider measuring culture directly [78]. Whereas we did find significant differences in attitudes toward institution-based trust between the French and U.S. subjects, a more determined attempt to show ecological validity would employ direct measures of culture.

\section{Conclusion}

THE OBJECTIVE OF THIS STUDY WAS TO FORMULATE and empirically test a model of trust in the IT artifact, directly applicable to m-commerce devices. This model includes system quality constructs of navigational structure and visual appeal, EOU, and culture. Each of these constructs has been identified as relevant to $\mathrm{m}$-commerce portals. Our findings show that all of these constructs are significant antecedents to trust in IT artifacts. Together, our results indicate that the influence of the IT artifact on users' trusting beliefs is substantial. As such, the characteristics and design of the IT artifact should not be overlooked in studies of trust, especially those involving new technologies.

Acknowledgments: The authors thank guest editor Izak Benbasat and three anonymous reviewers for their insightful comments throughout the review process. Special thanks also goes to Emmanuel Monod, Jessie Pallud, and Hirotoshi Takeda for their valuable assistance with data collection in France.

\section{Notes}

1. For the complete set of screenshots used in the experimental simulation, see Appendix F, available at http://anthonyvance.com/appendices/Trust-JMIS-2008.pdf.

2. The factor structure is reported in Table B3 of the appendices, available at http:// anthonyvance.com/appendices/Trust-JMIS-2008.pdf.

3. Refer to Table B4 of the appendices at http://anthonyvance.com/appendices/Trust-JMIS2008.pdf.

4. Detailed discussion of these tests may be found in Appendix A, available at http:// anthonyvance.com/appendices/Trust-JMIS-2008.pdf.

5. Both tests are described in greater detail in Appendix D, available at http://anthonyvance. com/appendices/Trust-JMIS-2008.pdf.

6. A summary of sample characteristics is provided in Appendix B, available at http:// anthonyvance.com/appendices/Trust-JMIS-2008.pdf.

7. For more information, see Appendix $\mathrm{C}$ at http://anthonyvance.com/appendices/TrustJMIS-2008.pdf.

\section{REFERENCES}

1. Ajzen, I., and Fishbein, M. Understanding Attitudes and Predicting Social Behavior. Englewood Cliffs, NJ: Prentice Hall, 1980. 
2. Ali, S. Telecommunications; browsing barriers: Consumers can use their cellphones to surf the Web; Why aren't they? Wall Street Journal (January 29, 2007), R4.

3. Ba, S., and Pavlou, P.A. Evidence of the effect of trust building technology in electronic markets: Price premiums and buyer behavior. MIS Quarterly, 26, 3 (2002), 243-268.

4. Bart, Y.; Shankar, V.; Sultan, F.; and Urban, G.L. Are the drivers and role of online trust the same for all Web sites and consumers? A large-scale exploratory empirical study. Journal of Marketing, 69, 4 (2005), 133-152.

5. Benbasat, I., and Zmud, R. The identity crisis within the IS discipline: Defining and communicating the discipline's core properties. MIS Quarterly, 27, 2 (2003), 183-194.

6. Blau, P.M. Exchange and Power in Social Life. New York: Wiley, 1964.

7. Boudreau, M.; Gefen, D.; and Straub, D.W. Validation in IS research: A state-of-the-art assessment. MIS Quarterly, 25, 1 (2001), 1-16.

8. Burton-Jones, A., and Straub, D.W. Reconceptualizing system usage: An approach and empirical test. Information Systems Research, 17, 3 (2006), 228-246.

9. Carte, T.A., and Russell, C.J. In pursuit of moderation: Nine common errors and their solutions. MIS Quarterly, 27, 3 (2003), 479-501.

10. Chellappa, R., and Pavlou, P.A. Perceived information security, financial liability, and consumer trust in electronic commerce transactions. Journal of Logistics Information Management, 15, 5-6 (2002), 358-368.

11. Chin, W.W.; Marcolin, B.L.; and Newsted, P.R. A partial least squares latent variable modeling approach for measuring interaction effects: Results from a Monte Carlo simulation study and an electronic mail emotion/adoption study. Information Systems Research, 14, 2 (2003), 189-217.

12. Cohen, J. Statistical Power Analysis for the Behavioral Sciences, 2d ed. Hillsdale, NJ: Lawrence Erlbaum, 1988.

13. Cyr, D.; Bonanni, C.; Bowes, J.; and Ilsever, J. Beyond trust: Web site preferences across cultures. Journal of Global Information Management, 13, 4 (2005), 25-54.

14. Davis, F.D. Perceived usefulness, perceived ease of use and user acceptance of information technology. MIS Quarterly, 13, 3 (September 1989), 319-340.

15. del Galdo, E.M., and Nielsen, J. (eds.). International User Interfaces. New York: John Wiley \& Sons, 1996.

16. DeLone, W.H., and McLean, E.R. Information systems success: The quest for the dependent variable. Information Systems Research, 3, 1 (1992), 60-95.

17. Doney, P.M.; Cannon, J.P.; and Mullen, M.R. Understanding the influence of national culture on the development of trust. Academy of Management Review, 23, 3 (1998), 601-620.

18. Featherman, M., and Pavlou, P.A. Predicting e-services adoption: A perceived risk facets perspective. International Journal of Human-Computer Studies, 59, 4 (2003), 451-474.

19. Field, J.M.; Heim, G.R.; and Sinha, K.K. Managing quality in the e-service system: Development and application of a process model. Productions and Operations Management, 13, 4 (2004), 291-306.

20. Fishbein, M., and Ajzen, I. Belief, Attitude, Intention, and Behavior: An Introduction to Theory and Research. Reading, MA: Addison-Wesley, 1975.

21. Fornell, C., and Larcker, D. Evaluating structural equation models with unobservable variables and measurement error. Journal of Marketing Research, 18, 1 (1981), 39-50.

22. Fromkin, H.L., and Streufert, S. Laboratory experimentation. In B. Dunnette (ed.), Handbook of Industrial and Organizational Psychology. Chicago: Rand McNally, 1976, pp. 415-465.

23. Fukuyama, F. Trust: The Social Virtues and the Creation of Prosperity. New York: Free Press, 1995.

24. Gefen, D. Building users' trust in freeware providers and the effects of this trust on users' perceptions of usefulness, ease of use and intended use. Ph.D. dissertation, Computer Information Systems Department, Georgia State University, Atlanta, 1997.

25. Gefen, D. E-commerce: The role of familiarity and trust. Omega, 28, 5 (2000), 725737.

26. Gefen, D. Reflections on the dimensions of trust and trustworthiness among online consumers. DATABASE for Advances in Information Systems, 33, 3 (2002), 38-53. 
27. Gefen, D., and Straub, D.W. Managing user trust in B2C e-services. e-Service Journal, 2, 2 (2003), 7-24.

28. Gefen, D.; Karahanna, E.; and Straub, D.W. Potential and repeat e-consumers: The role of and trust vis-à-vis TAM. IEEE Transactions on Engineering Management, 50, 3 (2003), $307-321$.

29. Gefen, D.; Karahanna, E.; and Straub, D.W. Trust and TAM in online shopping: An integrated model. MIS Quarterly, 27, 1 (2003) 51-90.

30. Gefen, D.; Straub, D.W.; and Boudreau, M. Structural equation modeling and regression: Guidelines for research practice. Communications of the AIS, 4, 7 (2000), 1-70.

31. Gefen, D.; Rose, G.M.; Warkentin, M.; and Pavlou, P.A. Cultural diversity and trust in IT adoption: A comparison of potential e-voters in the USA and South Africa. Journal of Global Information Management, 13, 1 (2005), 54-78.

32. Gefen, D.; Pavlou, P.A.; Benbasat, I.; McKnight, D.H.; Stewart, K.; and Straub, D.W. Should institutional trust matter in information systems research? Communications of the AIS, 19, 7 (2006), 205-222.

33. Gordon, M.E.; Slade, L.A.; and Schmitt, N. The "science of the sophomore" revisited: From conjecture to empiricism. Academy of Management Review, 11, 1 (1986), 191-207.

34. Halvey, M.; Keane, M.; and Smyth, B. Mobile Web surfing is the same as Web surfing. Communications of the ACM, 49, 3 (2006), 76-81.

35. Hasan, H., and Ditsa, G. The impact of culture on the adoption of IT: An interpretive study. Journal of Global Information Management, 7, 1 (1999) 5-15.

36. Hofstede, G. Culture's Consequences: International Differences in Work-Related Values. London: Sage, 1980.

37. Hofstede, G. Cultural dimensions in management and planning. Asia Pacific Journal of Management, 1, 2 (1984), 81-99.

38. House, R.J.; Hanges, P.J.; Javidan, M.; Dorfman, P.W.; and Gupta, V. Culture, Leadership, and Organizations. Thousand Oaks, CA: Sage, 2004.

39. Huff, L., and Kelley, L. Levels of organizational trust in individualist versus collectivist societies: A seven-nation study. Organization Science, 14, 1 (2003), 81-90.

40. Jarvenpaa, S.L., and Leidner, D.E. An information company in Mexico: Extending the resource-based view of the firm to a developing country context. Information Systems Research, 9, 4 (1998), 151-183.

41. Jarvis, C.B.; MacKenzie, S.B.; Podsakoff, P.; Mick, D.; and Bearden, W. A critical review of construct indicators and measurement model misspecification in marketing and consumer research. Journals of Consumer Research, 30, 2 (2003), 199-218.

42. Keil, M.; Tan, B.C.Y.; Wei, K.K.; and Saarinen, T. Cross-cultural study on escalation of commitment behavior in software projects. MIS Quarterly, 24, 2 (2000), 299-325.

43. Kim, J., and Moon, J.Y. Designing towards emotional usability in customer interfaces-Trustworthiness of cyber-banking system interfaces. Interacting with Computers, 10, 1 (1998), 1-29.

44. Kohn, A. Punished by Rewards. Boston: Houghton Mifflin, 1993.

45. Kohn, A. By all available means: Cameron and Pierce's defense of extrinsic motivators. Review of Educational Research, 66, 1 (1996), 1-4.

46. Komiak, S., and Benbasat, I. The effects of personalization and familiarity on trust and adoption of recommendation agents. MIS Quarterly, 30, 4 (2006), 941-960.

47. Lee, Y., and Benbasat, I. Interface design for mobile commerce. Communications of ACM, 46, 12 (2003), 48-52.

48. Leidner, D., and Kayworth, T. A review of culture in information systems research: Toward a theory of information technology culture conflict. MIS Quarterly, 30, 2 (2006), 357-399.

49. Lim, K.; Sia, C.; Lee, M.; and Benbasat, I. Do I trust you online, and if so, will I buy? An empirical study of two trust-building strategies. Journal of Management Information Systems, 23, 2 (Fall 2006) 233-266.

50. Lippert, S.K. An exploratory study into the relevance of trust in the context of information systems technology. Ph.D. dissertation, Department of Management Science, George Washington University, Washington, DC, 2001.

51. Loch, K.; Straub, D.; and Kamel, S. Diffusing the Internet in the Arab world: The role of social norms and technological culturation. IEEE Transactions on Engineering Management, 50, 1 (2003), 45-63. 
52. Loiacono, E.T. WebQual: A Web site quality instrument. Ph.D. dissertation, Department of Management Information Systems, University of Georgia, Athens, 2000.

53. Loiacono, E.T.; Watson, R.T.; and Goodhue, D.L. WebQual: An instrument for consumer evaluation of Web sites. International Journal of Electronic Commerce, 11, 3 (Spring 2007), 51-87.

54. Marcoulides, G., and Saunders, C. PLS: A silver bullet? MIS Quarterly, 30, 2 (2006), iii-ix.

55. Marcus, A., and Gould, E.W. Crosscurrents: Cultural dimensions and global Web userinterface design. Interactions, 7, 4 (July 2000), 32-46.

56. Mathieson, K.; Peacock, E.; and Chin, W. Extending the technology acceptance model: The influence of perceived user resources. DATABASE for Advances in Information Systems, 32, 3 (2001), 86-112.

57. McKnight, D.H. Trust in information technology. In G.B. Davis (ed.), The Blackwell Encyclopedia of Management, Vol. 7: Management Information Systems. Malden, MA: Blackwell, 2005, pp. 329-331.

58. McKnight, D.H.; Choudhury, V.; and Kacmar, C. Developing and validating trust measures for e-commerce: An integrative typology. Information Systems Research, 13, 3 (2002), 334-359.

59. McKnight, D.H.; Choudhury, V.; and Kacmar, C. The impact of initial consumer trust on intentions to transact with a Web site: A trust building model. Journal of Strategic Information Systems, 11, 3-4 (2002), 297-323.

60. McKnight, D.H.; Cummings, L.L.; and Chervany, N.L. Initial trust formation in new organizational relationships. Academy of Management Review, 23, 3 (1998), 473-490.

61. Montoya-Weiss, M.; Voss, G.; and Grewal, D. Determinants of online channel use and overall satisfaction with a relational, multichannel service provider. Journal of the Academy of Marketing Science, 31, 4 (2003), 448-458.

62. Nelson, R.; Todd, P.; and Wixom, B. Antecedents of information and system quality: An empirical examination within the context of data warehousing. Journal of Management Information Systems, 21, 4 (Spring 2005), 199-235.

63. Nunnally, J.C. Psychometric Theory. New York: McGraw-Hill, 1967.

64. Pavlou, P.A. Institution-based trust in interorganizational exchange relationships: The role of online B2B marketplaces on trust formation. Journal of Strategic Information Systems, 11, 3 (2002), 215-243.

65. Pavlou, P.A. Consumer acceptance of electronic commerce-Integrating trust and risk with the technology acceptance model. International Journal of Electronic Commerce, 7, 3 (Spring 2003), 69-103.

66. Pavlou, P., and Gefen, D. Building effective online marketplaces with institution-based trust. Information Systems Research, 15, 1 (2004), 37-59.

67. Pavlou, P., and Gefen, D. Psychological contract violation in online marketplaces: Antecedents, consequences, and moderating role. Information Systems Research, 16, 4 (2005), 372-399.

68. Petter, S.; Straub, D.W.; and Rai, A. Specification and validation of formative constructs in IS research. MIS Quarterly, 31, 4 (2007), 623-656.

69. Png, I.P.L.; Tan, B.C.Y.; and Wee, K.L. Dimensions of national culture and corporate adoption of IT infrastructure. IEEE Transactions on Engineering Management, 48, 1 (2001), 36-45.

70. Podsakoff, P.M.; MacKenzie, S.B.; Lee, J.-Y.; and Podsakoff, N.P. Common method biases in behavioral research: A critical review of the literature and recommended remedies. Journal of Applied Psychology, 88, 5 (2003), 879-903.

71. Qiu, L., and Benbasat, I. Online consumer trust and live help interfaces: The effects of text-to-speech voice and three-dimensional avatars. International Journal of Human-Computer Interaction, 19, 1 (2005), 75-94.

72. Ringle, C.M.; Wende, S.; and Will, A. Smart PLS. Hamburg, Germany: University of Hamburg, 2005.

73. Sadeh, N.M. M-Commerce: Technologies, Services, and Business Models. New York: John Wiley \& Sons, 2002.

74. Salam, A.F.; Rao, H.R.; and Pegels, C.C. Consumer-perceived risk in e-commerce transactions. Communications of the ACM, 46, 12 (2003), 325-331. 
75. Sarker, S., and Wells, J. Understanding mobile handheld device use and adoption. Communications of ACM, 46, 12 (2003), 35-40.

76. Seddon, P. A respecification and extension of the DeLone and McLean model of IS success. Information Systems Research, 8, 3 (1997), 240-253.

77. Siau, K., and Shen, Z. Building customer trust in mobile commerce. Communications of ACM, 46, 4 (2003), 91-94.

78. Srite, M., and Karahanna, E. The role of espoused national cultural values in technology acceptance. MIS Quarterly, 30, 3 (2006), 679-704.

79. Straub, D.W. Validating instruments in MIS research. MIS Quarterly, 13, 2 (1989), 147-166.

80. Straub, D.W. The effect of culture on IT diffusion: Email and fax in Japan and the U.S. Information Systems Research, 5, 1 (1994), 23-47.

81. Straub, D.W.; Keil, M.; and Brenner, W. Testing the technology acceptance model across cultures: A three country study. Information \& Management, 31, 1 (1997), 1-11.

82. Straub, D.W.; Loch, K.; Evaristo, R.; Karahanna, E.; and Srite, M. Toward a theory-based measurement of culture. Journal of Global Information Management, 10, 1 (2002), 13-23.

83. Thatcher, J.B.; Srite, M.; Stepina, L.P.; and Liu, Y. Culture, overload and personal innovativeness with information technology: Extending the nomological Net. Journal of Computer Information Systems, 44, 1 (2003), 74-81.

84. Tseng, S., and Fogg, B.J. Credibility and computing technology. Communications of the ACM, 42, 5 (1999), 39-44.

85. Wagner, A. The mobile storefront: Let your fingers do the shopping. Paper presented at the conference on Designing for User eXperience, San Francisco, November 3-5, 2005.

86. Wang, W., and Benbasat, I. Trust and adoption of online recommendation agents. Journal of the AIS, 6, 3 (2005), 72-101.

87. Wang, W., and Benbasat, I. Recommendation agents for electronic commerce: Effects of explanation facilities on trusting beliefs. Journal of Management Information Systems, 23, 4 (Spring 2007), 217-246.

88. Wixom, B., and Todd, P. A theoretical integration of user satisfaction and technology acceptance. Information Systems Research, 16, 1 (2005), 85-102.

89. Wolfinbarger, M., and Gilly, M.C. eTailQ: Dimensionalizing, measuring and predicting etail quality. Journal of Retailing, 79, 3 (2003), 183-198.

90. Wu, I.L., and Chen, E.L. An extension of trust and TAM model with TPB in the initial adoption of on-line tax: An empirical study. International Journal of Human-Computer Studies, 62, 6 (2005), 784-808.

91. Zaheer, S., and Zaheer, A. Trust across borders. Journal of International Business Studies, 37, 1 (2006), 21-29. 
Copyright of Journal of Management Information Systems is the property of M.E. Sharpe Inc. and its content may not be copied or emailed to multiple sites or posted to a listserv without the copyright holder's express written permission. However, users may print, download, or email articles for individual use. 